\title{
El malditismo de Fernando Vallejo como espectáculo melodramático
}

\author{
Fernando Vallejo's Mauditisme as Melodramatic Spectacle \\ O malditismo de Fernando Vallejo como espetáculo melodramático
}

\section{Héctor Hoyos}

STANFORD UNIVERSITY, ESTADOS UNIDOS

Profesor del Departamento de Culturas Iberoamericanas de la Universidad de Stanford, California, Estados Unidos. PhD, Universidad de Cornell, Nueva York, Estados Unidos. Ha publicado: "Aftershock: Naomi Klein and the Southern Cone" (Third Text, 2012); "García Márquez's Sublime Violence and the Eclipse of Colombian Literature" (Chasqui: Revista de Literatura Latinoamericana, 2006); Bogotá en su narrativa: la fragmentación como lugar literario (Universidad de los Andes, 2003). Coeditó el dossier "Theories of the Contemporary in South America" para la Revista de Estudios Hispánicos (2014). Su estudio Beyond Bolaño: The Global Latin American Novel aparecerá en 2015 bajo el sello de Columbia University Press. Correo electrónico: hoyos@stanford.edu

Traducción de Gabriela Andicoechea, estudiante de postgrado en la Universidad de Stanford y Magíster en Literatura Hispana de la Universidad de Virginia. Correo electrónico: gandicoe@stanford.edu Artículo de reflexión

Documento accesible en línea desde la siguiente dirección: http://revistas.javeriana.edu.co doi:10.11144/Javeriana.CL19-37.emdf 


\section{Resumen}

El análisis de Héctor Hoyos se aproxima al arte de provocación de Vallejo como un espectáculo que subvierte la estructura afectiva del melodrama. En el presente artículo, Hoyos propone que tanto en $L a$ virgen de los sicarios como en La puta de babilonia la voz de Vallejo, más allá de buscar simplemente escandalizar a su público, aprovecha sobre todo la oportunidad para insertarse en la coyuntura de la reproducción mediática, del espectáculo melodramático montado en torno a los íconos de Pablo Escobar y Juan Pablo II. El malditismo paródico de Vallejo es para Hoyos tardío y espectacular y está sostenido por el melodrama, un melodrama de fetichismos, reducciones y lugares comunes que - en medio de rancheras, tangos, villanos y brillantes corazones rojosVallejo busca trastornar desde adentro.

Palabras clave: Fernando Vallejo; malditismo; melodrama; $L a$ virgen de los sicarios

\section{Abstract}

Héctor Hoyos analyzes Vallejo's art of provocation as a spectacle that subverts the affective structure of melodrama. In the present article, Hoyos suggests that both La virgen de los sicarios and La puta de babilonia, beyond simply seeking to scandalize their public, serve as an occasion for Vallejo to insert himself in mediatic reproduction. Specifically, in a conjuncture marked of melodramatic spectacularization of the icons of Pablo Escobar and John Paul II. The parodic mauditisme of Vallejo is, for Hoyos, late and spectacular. It is one supported by melodrama, coupled with fetishism, simplifications and common places that, immersed in rancheras, tangos, villains, and bright red hearts, Vallejo intends to unhinge from within.

Key words: Fernando Vallejo; mauditisme; melodrama; La virgen de los sicarios

\section{Resumo}

A análise de Héctor Hoyos se aproxima da arte de provocação de Vallejo como um espetáculo que subverte a estrutura afetiva do melodrama. No presente artigo, Hoyos prop õe que tanto em La virgen de los sicarios como em La puta de babilonia a voz de Vallejo, mais além de buscar simplesmente escandalizar a seu público, aproveita, sobretudo, a oportunidade para inserir-se na conjuntura de reprodução midiática, do espetáculo melodramático montado em torno dos ícones de Pablo Escobar e João Paulo II. O malditismo paródico de Vallejo é para Hoyos tardio e espetacular, e está sustentado pelo melodrama, um melodrama de fetichismos, reduções e lugares comuns que em meio à rancheras, tangos, vilões $\mathrm{e}$ brilhantes corações vermelhos, Vallejo busca transtornar a partir de dentro.

Palavras-chave: Fernando Vallejo; malditismo; melodrama; La virgen de los sicarios

RECIBIDO: 1 DE JULIO DE 2014. EVALUADO: 22 DE AGOSTO DE 2014. DISPONIBLE EN LÍNEA 15 DE ENERO DE 2015.

Cómo citar este artículo:

Hoyos, Héctor. "El malditismo de Fernando Vallejo como espectáculo melodramático". Cuadernos de Literatura 19. 37 (2015): 169-176. doi:10.11144/Javeriana.CL19-37.emdf 
EN EL 2011, en su discurso de aceptación del Premio de Literatura en Lenguas Romances en la Feria Internacional del Libro de Guadalajara, Fernando Vallejo comenzó por afirmar que cuando había llegado a la Plaza Garibaldi hacía cuarenta años, se había sentido como un sacerdote de un país tercermundista entrando al Vaticano por primera vez. Al igual que muchos colombianos, Vallejo creció escuchando rancheras. De ahí la colorida expresión, que también hace parte del discurso, de que su primera comunión fuera con tequila. Habiendo cautivado a su audiencia en Jalisco con esas menciones a la cultura popular mexicana, el autor prosiguió a iterar sus tropos recurrentes acerca de los derechos de los animales, el control de la natalidad, la lucha contra la corrupción, etcétera. El discurso es representativo del estilo de Vallejo: un argumento teológico reposado en una cama de sensacionalismo; una mezcla idiosincrática de alta cultura y cultura popular, de formas cursi. También cantó e invocó a Juan Rulfo en el estado natal de aquel autor. Jorge Volpi, que presentó al galardonado, hizo una referencia velada a la inesperada relevancia que La virgen de los sicarios adquiría en México. Se refería, por supuesto, a la tan mentada "colombianización" de México (la degradación de la guerra contra las drogas), que se hacía sentir.

En este breve ensayo especularé sobre la visión de mundo de Vallejo, la cual, propongo, permite que Ciudad de México, Medellín y Roma sean todas capitales globales. También me propongo caracterizar su forma peculiar de mauditisme o malditismo, que, a mi modo de ver, busca transformar el espectáculo melodramático desde su interior.

En los años sesenta del siglo pasado, Guy Debord se encontró en Francia con lo que denominó una sociedad del espectáculo. Según propone, el espectáculo es "capital en un grado tal de acumulación que se transforma en imagen" (\$34). Como sucede con la ideología, el individuo no es consciente del espectáculo cuando se encuentra sometido a él. Sin embargo, a diferencia de la ideología, el espectáculo se caracteriza por su cualidad sensorial, abarcante, de inmersión. El fetichismo de la mercancía es allí tan predominante que no solo logra convertir a los seres humanos en bienes de consumo, sino también todo aquello que estos ven y escuchan. Renunciamos a la vida y la intercambiamos por una representación de ella. Nos volvemos incapaces de percibir las relaciones sociales que hacen posible a las imágenes; las damos por sentadas, como si éstas no tuvieran referentes, o ni siquiera hubieran sido producidas. El espectáculo, según afirma Debord, "no es un conjunto de imágenes, sino una relación social entre personas, mediatizada a través de las imágenes" (\$4).

Flash forward a la Colombia de los años noventa. Los alegres anuncios de Citroën no imponen una sensación de normalidad tras la reciente protesta 
estudiantil, como sucedía en Francia. En cambio, son el fútbol y las telenovelas las que se imponen sobre la posibilidad, en su momento bastante factible, de que los carteles del narcotráfico se tomaran el país (esta incongruencia entre fútbol y política es una de las tramas secundarias más notables de Perder es cuestión de método, 1997, de Santiago Gamboa). Todos las esferas de la sociedad están en peligro de terminar colapsando. Las élites se rinden ante la presión que ejercen los narcotraficantes, tal y como lo reconstruye García Márquez con sumo cuidado en Noticia de un secuestro (1996). En 1991, la nación restableció un nuevo contrato social por medio de una Constitución nacida en medio de señales ambiguas que indicaban un posible cese de hostilidades con algunos grupos armados, y un recrudecimiento con otros grupos. Pero, a pesar de todo ello, siempre es posible refugiarse en el melodrama. $\mathrm{O}$ casi siempre: cuando el defensa de la Selección Colombia, Andrés Escobar, es asesinado en 1994 (un evento traumático revisitado en el 2009 en la novela Autogol, de Ricardo Silva), ni siquiera el espectáculo fue capaz de ofrecer solaz.

Hago referencia a estos eventos por dos razones. Primero, porque hacerlo le quita algo de su carácter de excepción a Vallejo. Tal es la tendencia natural en los estudios concentrados en un autor específico, como la presente compilación. Y, segundo, porque esto nos permite apreciar con mayor nitidez lo que hace Vallejo. Él, a diferencia del resto de los autores mencionados, no es un intelectual equilibrado que analiza un fenómeno del pasado para poder después ofrecer una explicación de este. Ni siquiera brinda una caricatura de explicación, como lo hace Gamboa. Vallejo es alguien que aprovecha cualquier oportunidad de participar en el espectáculo melodramático para darle un nuevo sentido.

De este modo, publicó La virgen de los sicarios en 1994, menos de un año después de que Pablo Escobar fuera cazado por los tejados de Medellín (imagen inmortalizada por Fernando Botero, en 1999). Con el mismo sentido de oportunidad, Vallejo publica en 2007, tras la muerte del papa Juan Pablo II, La puta de Babilonia. Hay algo en el poder tanto secular como religioso que detentan estos dos hombres que fascina a Vallejo. Fernando, el protagonista de La virgen de los sicarios, deambula por Medellín yendo de iglesia en iglesia. Mentalmente también visita "La Catedral", como bien se llamaba a la cárcel en la cual Escobar, un papa rodeado de lujo, pasó algún tiempo preso. Las imágenes de Escobar abundaban en las noticias; su cara se había convertido en el punctum de la guerra contra las drogas. Mientras estaba fugado, se encontraba por doquier y en ningún lado al mismo tiempo; de manera análoga al ícono ubicuo del Sagrado Corazón de Jesús, Escobar parecía no tener un referente en la vida cotidiana. Y después apareció su cadáver. Durante varios días su cuerpo fue exhibido en todas las 
portadas de los periódicos, incluidas también fotografías de la autopsia. Para la mayoría de colombianos, nunca fue un verdadero cadáver, sino una imagen. El espectáculo melodramático alcanzó su punto culminante y prosiguió. En la prosa lírica de Vallejo:

Desde las terrazas de mi apartamento oí los tiros: tatatatatá. Dos minutos de ráfagas de metralleta y ya, listo, don Pablo se desplomó con su mito. Lo tumbaron en un tejado huyendo, como a un gato en desgracia. Dos tiros tan solo le pegaron, por el su lado izquierdo: uno por el su cuello, otro por la su oreja. Se despanzurró como el susodicho gato sobre el "entejado", su tejado caliente, quebrando, entre él y sus veinticinco mil perseguidores, más de un millón de tejas en la persecución. La recompensa no me la gané yo, pero estuve a tres cuadras.

Muerto el gran contratador de sicarios, mi pobre Alexis se quedó sin trabajo. Fue entonces cuando lo conocí. Por eso los acontecimientos nacionales están ligados a los personales, y las pobres, ramplonas vidas de los humildes tramadas con las de los grandes. (Vallejo 71-2)

La trama de La virgen trata acerca del vacío que dejó Escobar; mientras que la de La puta, del que dejó Juan Pablo II. Alexis, el sicario menor de edad a quien Fernando ama, carece de un propósito en la vida. Distrae su apatía viendo televisión, pero eso solo funciona hasta que su amante, un filólogo viejo y cascarrabias, amenaza con suicidarse. Aquél se siente agobiado por el estrépito de Medellín, particularmente por la música chillona de los taxis - equivalente, por cierto, a la que el verdadero Vallejo celebra en Guadalajara - y por la voz aguda del presidente hablando en la televisión. Alexis le dispara al televisor y, al hacerlo, salva la vida de Fernando. La desventaja es que el vacío en su vida cobra vida propia, y el muchacho sale a cometer una oleada de asesinatos. ¿Acaso no podemos apreciar esta desolación como la secuela de la muerte de un dios? Como he argumentado en otro ensayo, La virgen funde lo divino con lo demoniaco, ofreciendo algunas seudopruebas acerca de la existencia de Dios (teodiceas) y el Diablo. Fernando declara que Dios existe cuando mira a los ojos a un niño de la calle drogado o cuando ve buitres volando por encima de la ciudad. Pero no es hasta cuando observa los ojos del cadáver de uno de sus amantes y, presuntamente, se topa con su propia reflexión en ellos, que atestigua la maldad de Dios.

Este satanismo "juguetón”, como lo ha notado Fernando Díaz Ruiz, alinea a Vallejo con la larga tradición del malditismo. Pero, a diferencia de Díaz, quien lee a Vallejo en relación con Meyer y Baudrillard, y concluye que el autor colombiano es un Rimbaud o Lautréamont contemporáneo, me parece que no es 
posible apreciar la especificidad de la apropiación de esa tradición por parte de Vallejo si no tomamos en cuenta su carácter tardío y espectacular. Tardío porque, a pesar de que Colombia es un país clerical y conservador, que se escandaliza, no es posible que las obras de Vallejo causen el efecto que tuvo en su momento Una temporada en el infierno (1873). Por supuesto, su evocación de una versión idealizada de la maldad se suma al desafío que la sexualidad gay puede tener para los sectores más reaccionarios de la sociedad. Pero no hay burgueses a la francesa a los cuales épater, ni novedad en un sentido profundo.

Vallejo es el primero en reconocer su propio linaje en las obras de Fernando González, Porfirio Barba Jacob y José Asunción Silva. El escandalizar la moral cristiana es secundario al fin principal, que a mi modo de ver consiste en revelar las creencias escatológicas de los medios de comunicación modernos. Pablo Escobar es o un demonio o una deidad caída. No es ni más ni menos que un gato para un autor que considera a los animales como la única cosa realmente sagrada (recuérdese que en Guadalajara Vallejo compara al expresidente Vicente Fox con un gallo y un burro). Las imágenes que nos presentan los medios de comunicación se convierten en iconografía religiosa por su capacidad de congregarnos, de introducir las esferas del poder en la intimidad de nuestros hogares y por su habilidad de representar algo más importante que nosotros mismos. Los medios de información ofrecen el consuelo que previamente se reservaba solo para el cristianismo, con sus corazones cubiertos en llamas y costados sangrantes. "La sensación de estar a salvo de la calamidad estimula el interés en la contemplación de imágenes dolorosas", anota Susan Sontag, "y esa contemplación supone y fortalece la sensación de estar a salvo" (251). La guerra "contra las drogas" solo existe en la televisión; el verdadero combate involucra a personas, no a sustancias. Es absurdo declarar una guerra en nombre de las drogas; ahora bien, las cruzadas, aunque se convocaban por razones abstractas y sagradas, conducen a muertes muy concretas y a los mórbidos placeres de la contemplación. Vallejo contradice esa lógica e interrumpe el tipo de mirar que la alienta.

El melodrama escenifica las contradicciones sociales y reduce los matices morales a una lucha entre el bien y el mal. No es posible realizar un trabajo elaborativo (working through) de la contradicción social a través del melodrama. En Colombia, una empleada doméstica y sus empleadores pueden ver la misma telenovela acerca de, por ejemplo, cómo una mujer asciende de clase social por medio de una cirugía de aumento de senos (Sin tetas no hay paraíso) o de cómo una recolectora de café logra formar parte de la clase gerencial por medio de una combinación de educación, tenacidad y amor por su jefe (Café con aroma de mujer). El fútbol, dentro de la experiencia latinoamericana, es similarmente 
melodramático: el mundo acaba cada vez que Boca Juniors se enfrenta ante River Plate, Nacional-Medellín, Chivas-América. Aquí se entrelazan tres hilos: el melodrama, el espectaculismo y la vida afectiva del cristianismo popular, llena de sacrificio, redención, iconicidad y promesa de trascendencia. La mayoría de los jugadores de fútbol tienen una historia de ascensión social prodigiosa; cada semana se juegan sus nuevos estatus ante la amenaza de las lesiones, el fracaso y, según parece, el destino mismo. "El melodrama", escribe Jesús Martín Barbero, "[es] mucho de lo que [los latinoamericanos] somos [...] y de lo que soñamos ser, el robo de la identidad, la nostalgia y la rabia. En la forma de tango o de telenovela, de cine mexicano o de crónica roja el melodrama trabaja en estas tierras una veta profunda de nuestro imaginario colectivo" (262-63).

Los grandes corazones rojos son el epítome kitsch del melodrama. Tal es una de las principales imágenes recurrentes en la obra vallejiana; palpitan al final de Los días azules (1985), al comienzo de La virgen (1994), en una escena retrospectiva en El desbarrancadero (2003), entre otros pasajes. Esta imagen insistente alude, en diferentes momentos, al Sagrado Corazón de Jesús, al fin de la infancia, a la voluntad de vivir, al liberalismo, al mundo, a Colombia - y, como me gustaría terminar de enfatizar, a la afectividad melodramática-:

[E]levamos el globo más grande que hubieran visto los cielos de Antioquia, un rombo de ciento veinte pliegos inmenso, rojo, rojo, rojo para que resaltara sobre el cielo azul [... el] humo es como quien dice su alma, y la candileja el corazón. Cuando se llenan de humo y empiezan a jalar, los que los están elevando sueltan, soltamos, y el globo se va yendo, yendo al cielo con el corazón encendido, palpitando, como el Corazón de Jesús. (Vallejo 7)

Como ilustra la imagen central de la escena, un corazón flotante, el melodrama es el fundamento afectivo que sostiene el malditismo paródico de Vallejo. En efecto, Vallejo cuenta la historia de la Iglesia como si Ella fuera la villana de la telenovela. Y mientras coquetea con la herejía, subvierte las normas tácitas del espectáculo melodramático. Vallejo no busca denunciar como ideología a este tipo de espectáculo - ni elucidar una verdad oculta, como lo haría otro tipo de intelectual- . Al contrario, busca participar en el espectáculo y trastocar sus normas, de manera similar a la práctica de détournement de Debord. De allí la operación de queering de Pablo Escobar, o la de transformar la gran narrativa nacional de auge y caída, rica en machismo y en heteronormatividad. Y subvierte de igual forma el marianismo, contra el cual se enfrenta tanto en La virgen como en otras obras, con hipérbole misógina. El arte de provocación vallejiano logra ser efectivo no tanto por los conflictos particulares que aborda, sino porque reta 
una estructura afectiva subyacente: tanto en las rancheras y los tangos como en los vallenatos, las madres son sagradas pero las mujeres son siempre viles.

Los íconos religiosos y los de los medios de comunicación consiguen una complexio oppositorum: reconcilian oposiciones y mantienen a raya contradicciones. Un ícono modesto, Vallejo asume el papel de la Virgen de los sicarios, pues encarna la contradicción. Él, al igual que el resto de los Homo sapiens, es un animal. Así que existe una clara tensión entre sus apasionados argumentos contra la reproducción humana y sus brotes de amor por "los animales". Los dioses no existen, sin embargo, y nosotros no somos dioses para los animales. Lo que realmente importa es la vida, tema principal de la novela El don de la vida (2010) que, no obstante, queda fuera del alcance de este trabajo. Ante la pregunta de si Vallejo exacerba o apacigua la contradicción, la respuesta depende de cuánto de la provocación se tomen a pecho los lectores. En Guadalajara, Vallejo denunció a la policía secreta del Partido Revolucionario Institucional (PRI) como el nido de los carteles mexicanos. Quizá ello sea afirmar lo obvio, pero su mordacidad y efectividad radican en saber trastornar un festejo dedicado a otro tipo de lugares comunes.

\section{Obras citadas}

Debord, Guy. La sociedad del espectáculo. Buenos Aires: La Marca, 2008.

Díaz Ruiz, Fernando. "Fernando Vallejo y la estirpe inagotable del escritor maldito". Caravelle: Cahiers du Monde Hispanique et Luso-brésilien 89 (2007): 231-48.

Hoyos, Héctor. "La racionalidad herética de Fernando Vallejo y el derecho a la felicidad". Revista de Estudios Sociales 35 (2010): 113-22.

Martín-Barbero, Jesús. De los medios a las mediaciones: comunicación, cultura y hegemonía. 6. ed. Barcelona: Anthropos, 2010.

Sontag, Susan. Sobre la fotografía. Trad. Carlos Gardiní. Madrid: Alfaguara, 2006.

Vallejo, Fernando. La virgen de los sicarios. Bogotá: Santillana, 1994.

-. "Discurso de Fernando Vallejo en la recepción del Premio FIL de Literatura en Lenguas Romances". Feria Internacional del Libro de Guadalajara. Guadalajara, Jalisco, 26 de noviembre de 2011. 